[MARIA DE FATIMA DA S. COSTA G. DE MATTOS]

Doutora em Artes. Professora no Programa de Pós-Graduação em Educação.

Centro Universitário Moura Lacerda.

E-mail: mffmattos@gmail.com

\title{
A importância do traje na obra de Watteau
}

Resenha de: LIMA, Laura Ferrazza de. Quando a Arte encontra a Moda - a obra de Antoine Watteau na França do século XVIII. Porto Alegre: Zouk, 2018. 304 p. 
Quando soube deste livro pensei: "que bom, uma historiadora da arte brasileira ter abordado a moda por meio do estudo de imagens que documentam os costumes na França do século XVIII". Com o exemplar do livro em mãos, percebi que tal investigação ia muito mais além. Quando a Arte encontra a Moda dedica-se à história e à obra do pintor Watteau, no século XVIII, e o papel da representação do vestuário (le costume) nas suas pinturas e gravuras, especialmente no conjunto das Figures de différents caractères, ainda pouco conhecido, incluindo as Figures de modes. 0 subtítulo da obra faz referência à sua tese de doutoramento em História - Na trama das aparências: moda e arte na obra de Antoine Watteau (1684-1721), (LIMA, 2015) -, que deu origem a este livro, e que nos remete à questão da identidade discutida por meio da análise de algumas obras, tendo pontuado de maneira brilhante a característica dos termos "vestido Watteau" e "prega Watteau" na história da moda e da indumentária.

A obra

Jean-Antoine Watteau (1684-1721), de origem flamenga e com uma reputação ilibada, conquistou vários amigos em Paris, dentre os quais alguns notáveis da sociedade, o que Ihe facilitou a formação de um discreto círculo social. Dono de um espírito inconstante, irrequieto e intimista, destacava-se por sua elegância e pelas boas maneiras, o que reverberava nas suas obras de pintura. Sua entrada na Academia Real de Artes em 1717 ocorreu por meio de uma pintura que representa uma "Viagem de peregrinos para a Ilha de Citera", afirmando o reconhecimento do seu talento, fato esse que, pessoalmente, acreditava trazer-lhe prestígio.

Em 1719 fez uma viagem para a Inglaterra em busca de um médico famoso, em virtude de uma tuberculose, mas o clima úmido causou uma piora do seu estado de saúde. Porém, nessa viagem e estada em Londres, conheceu o prazer de obter dinheiro pela venda e pelo reconhecimento de suas obras.

Como um apreciador do teatro e, especialmente, dos trajes femininos, a maioria dos seus quadros na França foi adquirida pela burguesia que valorizava, à época, um tipo de ar contemplativo nas figuras expressas pelo pintor, além da peculiar habilidade de Watteau em representar os tecidos com seu caimento impecável, texturas e dobras, ao ponto de suscitar a identificação do tecido pelo observador, razão pela qual chegou a ser visto por alguns críticos como "pintor de gênero".

Sofrendo de uma tuberculose incurável, tinha 37 anos quando faleceu, deixando uma vasta produção: em torno de 200 pinturas a óleo, aproximadamente 400 gravuras, além de vários e valiosos trabalhos de decoração de interiores. 
Como artista, pressentiu e observou de perto a evolução dos costumes que caracterizaram o século XVIII na França, e, como um bom observador das ruas, os tipos e trajes nos teatros e óperas. Suas referências visuais advinham da pintura do século XVI, tanto dos pintores holandeses como dos coloristas venezianos. Watteau possuía uma paleta de cores sutis e delicadas, "pastéis", tendo desenvolvido o gosto por uma pintura clara e propensa a uma temática mais amena. Nas formas de representar o mundo real, a arte desse período tornou-se um escapismo no qual a música e o teatro, as festas e fantasias reinavam em um mundo de sonhos e aparência.

Mas qual foi o papel do traje na obra de Watteau? A resposta a tal pergunta, proposta pela autora do livro, a pesquisadora e historiadora da arte Laura Ferrazza de Lima, mostra que o desenho das vestimentas feito pelo artista e das cenas onde as coloca nos permitem conhecer uma faceta da sua personalidade, na qual se revelava o gosto pela música, pela literatura e pelo teatro, próprios de um homem culto e artista notável. Assim, a pesquisadora, debruçada sobre a história da arte e da indumentária, passa a analisar algumas das obras do artista com o intuito de traçar uma relação entre a arte e a moda francesa no século XVIII. Lima pontua caracteristicas a partir das referências sobre o universo dos trajes e da elegância feminina, evidenciando o caráter plural da arte no período, tanto nas ilustrações de moda como nos retratos dos membros da alta sociedade, inclusive os artistas e os músicos, e até mesmo alguns camponeses. Em contrapartida, pessoas de origem mais modesta, como os criados e outros tipos populares, eram identificados por Watteau por meio de tecidos mais rústicos, dentre os quais o algodão, como era o costume da época.

Contudo, era nos desenhos que o pintor melhor expressava seus tipos masculino e feminino, para depois reproduzi-los em suas telas, valendo-se de características próprias para os cabelos e maquiagem, que compunham a questão das aparências, tão caras a essa sociedade. 0 traje elegante foi uma constante em suas obras, retratando com isso cenas de caráter cerimonial, como era o gosto do novo público apreciador. As damas, por sua vez, sempre vestidas à última moda, foram reproduzidas não só na pintura, como também nas gravuras, especialmente no pequeno conjunto denominado Figuras de Moda.

Um quadro, dentre as obras mais elogiadas da pintura de Watteau, e considerado "síntese da sociedade francesa do século XVIII", é A tabuleta de Gersaint (figura 1). Na loja desse vendedor de quadros, que é um testemunho dos magníficos desenhos do artista, os personagens em seus trajes carregam códigos imagéticos que ajudam a compreender a sociedade da época e as escolhas do artista. 
Figura 1. Antoine Watteau. L'enseigne de Gersaint (A tabuleta de Gersaint). 1721. Óleo sobre tela, 166 × 306 cm. Palácio de Chartlottemburg, Berlim.

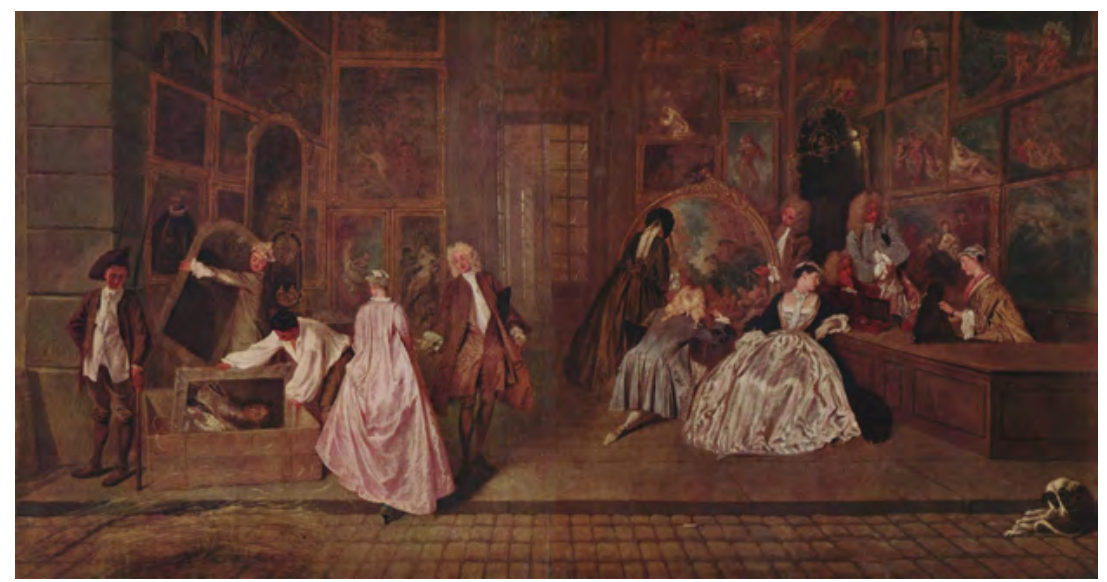

Fonte: https://fr.wikipedia.org/wiki/Fichier:Antoine_Watteau_047.jpg

É também nessa obra que o pintor apresenta a peça de vestuário que ficou conhecida como "vestido Watteau", ou, como também aparece nos compêndios de história da indumentária, "vestido com pregas Watteau", que pode ser observado na referida obra pela posição das figuras femininas, que, nos seus movimentos, favorecem a visão frente e costas, evidenciando a parte traseira do vestido. Poucos pintores deram tamanha ênfase a essa postura feminina como forma de expressão individual.

Como bem ressalta a autora, entre 1705 e 1715 surgiu a moda dos vestidos não rígidos, denominados "vestidos volantes", que resultaram na nomenclatura dos "vestidos Watteau", uma vez que, segundo François Boucher (2009), o artista não se pronunciou a respeito, ficando patente a denominação. É uma peça com pregas verticais, que partem do ombro, trazendo plissados transversais nas mangas, fixados por um cordãozinho e um botão. A denominação "vestido Watteau" só foi agregada ao nome do pintor no século seguinte (XIX). Mesmo não tendo ele criado o termo que identifica a peça do vestuário, sua obra a eternizou, marcando a moda feminina no início do século XVIII.

Outra belíssima e inédita análise que a pesquisa de Laura Ferrazza de Lima apresenta é sobre o conjunto de gravuras Figures de différents caracteres. Esse conjunto faz parte do chamado "Recueil Jullienne", que se constitui em uma compilação de obras do artista. Jean de Jullienne era amigo de Watteau e, após a sua morte, publicou em 1726-1728 dois grandes livros intitulados Figures de différents caractères, reunindo 351 gravuras mediante uma seleção dos desenhos e, em 1775, L'ouvre d'Antoine Watteau, com mais 271 gravuras sobre seus quadros. Jullienne possuía uma notável coleção de obras de Watteau, adquiridas de tempos em tempos e 
de acordo com o seu gosto pessoal - 40 quadros e 450 desenhos -, tendo sido considerado um colecionador de arte do século XVIII e um especialista na obra do pintor, além de um de seus biógrafos.

0 livro Figures de différents caractères mostra uma diversidade temática nos desenhos de Watteau, dedicados, em especial, às representações da figura humana. Laura novamente analisa de maneira apropriada e minuciosa algumas obras do pintor, desenhista e gravurista, dividindo suas gravuras em três grandes grupos: figuras isoladas, figuras na paisagem, paisagem sem figura. Assim, observa que as pessoas representadas pelo pintor eram divididas em tipos sociais, reconhecidos por suas vestimentas e atitudes: tipos teatrais, formados por personagens da commedia dell'arte italiana, ou da comédie française, sendo os mais recorrentes o pierrô e o briguela; outros são retratados em traje de peregrinos; outros, ainda, em passos de dança; músicos e musicistas com seus instrumentos, e alguns raros tipos alegóricos ou mitológicos.

Também aparece com frequência na literatura sobre o pintor uma outra criação, os "casais de Watteau", nos quais a mulher protagoniza as cenas. Mas é a interação entre os dois por meio do jogo da sedução, da gestualidade e da vestimenta que toma o quadro, muitas vezes, uma expressão constante das classes aristocráticas. A autora então nos diz "são as formas de viver 0 amor e a conquista que permeiam a representação desses casais" (p. 212).

A intenção da pesquisadora não foi chegar a definições categóricas, mas tentar entender como ocorre o entrelaçamento entre a arte e a moda na produção de Watteau, bem como a permanência de suas obras no tempo, ao conseguir reunir temas da Antiguidade com os desejos da geração romântica, indo muito além da superficialidade atribuída durante muito tempo à pintura do artista. A pesquisadora e historiadora da arte Laura Ferrazza de Lima deixa registrada em seu livro a vitória sobre um desafio incrivel, que foi o de analisar a obra de um pintor pelo viés da moda.

Trata-se de uma importante leitura para os historiadores da arte, da indumentária e da moda em geral, e para quem mais permitir se deixar enlevar pelo espetáculo de uma época, na qual a vida evocava a alegria de viver, a sedução e a felicidade.

\section{REFERÊNCIAS}


abepem

ASSOCIAÇÃO BRASILEIRA DE

ESTUDOS E PESQUISAS EM MODA 